\title{
Self-Esteem and Locus of Causality as Vulnerability Factors for the Development of Actual/Ideal Self-Discrepancies in Late Childhood
}

\author{
Lisa Di Blas, Annunziata Cepollaro \\ Department of Life Sciences, Unit of Psychology "G. Kanizsa", University of Trieste, Italy
}

\begin{abstract}
Self-discrepancies influence psychological well-being and self-acceptance across several domains. Middle to late childhood is a critical age for the development of self-discrepancies (SD). The present study was aimed at investigating antecedents of actual/ideal self-discrepancies in 9- to 11-year-old children by adopting a repeated measure design, with two measurement occasions. At the baseline (T1), children $(N=261)$ completed a self-esteem questionnaire, a measure of actual/ideal SDs we developed around the Five Factor Model domains, and the Strengths and Difficulties Questionnaire; 4 months later (T2) a subsample $(N=96)$ provided self-ratings again. Children's parents $(N=195)$ referred on their own feelings towards their children along the Profile of Mood States as well as on their perceived locus of control of their children's undesirable behaviors; a subsample of parents $(N=80)$ provided ratings again 4 months later. Principal component analyses from children's self-discrepancies at T1 yielded four domains: Intellect, Emotional Stability, Impulse Control, and Sociability. Self-rated discrepancies across time were moderately stable. Concurrently, higher SDs in Intellect were associated with lower children's self-esteem. Crosslagged pattern analyses showed that lower self-esteem predicted increases in children's SDs, but not vice versa; in addition, change levels in SDs were correlated with change levels in self-esteem. Parents' perceived internal locus of causality of their children's undesirable behaviors also accounted for changes in children's SDs. Parents' feelings of depression accounted for increases in girls' SDs. The present findings further support the association between self-esteem and SDs, indicate the direction of association across time, and suggest possible mechanisms by which parents affect the development of the children's self-views.
\end{abstract}

Keyword: personality development, self-discrepancies, self-esteem, locus of causality, child/parent correlations

Lisa Di Blas, Department of Life Sciences, Unit of Psychology "G. Kanizsa", University of Trieste, via Weiss 2 (pal. Q), 34100 Trieste, Italy. E-mail: diblali@ units.it

\section{Authors' note}

Funding: This research project was supported by the University of Trieste (FRA 2014).

Participants: We thank all the children and their parents who took part in the study here presented; we also thank teachers and the Head of the elementary school "F. Giampaglia" (Ercolano, NA) for their cooperation. We also thank two anonymous reviewers for their helpful comments. 


\section{Introduction}

Self-discrepancies represent incongruencies that emerge in the self-system between different aspects of the self, specifically beliefs and self-regulatory standards. In his self-discrepancy theory (SDT), Higgins (1987) focused on discrepancies between how a person believes s/he actually is (actual self) and how s/he thinks of her/himself in relation to his/her moral duties and responsibilities (ought self) or his/her aspirations, hopes, and wishes (ideal self). Higgins proposed that these three domains of the self in combination with own or significant other's standpoint on the self represent different types of self-discrepancies, each of which is associated with different negative emotional states. Actual own/ideal own discrepancies, for example, have been demonstrated to make a person more vulnerable to dejection-related emotions (Higgins, 1987) as well as to lower selfesteem levels (Moretti \& Higgins, 1990). In the present study, we focused our attention on actual own/ideal own (A/I) discrepancies and explored how A/I selfdiscrepancies and self-esteem are associated across time, in late childhood.

Actual/ideal self-discrepancies emerge in the absence of positive outcomes. Developmentally, Higgins (1989) proposed that significant adults appraise children in terms of how children respond to adults' hopes and aspirations. To the extent that the adult emphasizes attention on positive outcomes and the child progressively directs his/her focus on such outcomes, ideal standards become the child's regulatory focus, his/her self-guides. Moretti and Higgins (1999) defined developmental stages across which children construct more and more complex self-representation in relation to interpersonal contexts and parental socialization strategies. Specifically, in late childhood (9-11 years), when children are increasingly capable of organizing self-views into trait-like categories and provide consistent self-ratings (Di Blas, Grassi, Luccio, \& Momentè, 2012; Harter, 1999, 2006), children become more sensitive to inconsistent information, with discrepancies between self-relevant beliefs and others' standpoints turning out into potentially stressing psychological situations and feelings of guilt and embarrassment. Later, the self-system become progressively more and more articulated: Adolescents are able to compare and strive to integrate actual self-perceptions in relations to several possible selves simultaneously (Harter, 1999; Higgins, 1987). Accordingly, Oosterwegel and Oppenheimer (2002) found a rapid increase in the awareness of self-incongruencies between 12 to 14 years. They also observed that discrepancies related to reflected appraisal of significant others' expectancies were negatively associated with wellbeing and positively with feelings of confusion, from middle childhood to late adolescence. Remarkably, self-guides that develop since childhood constitute structural domains of the self-system and they are relatively stable across time. In fact, in a 3-year longitudinal study involving young university students, Strauman (1996) showed that ideal self-views were more stable than actual self-perceptions. Findings from his study also demonstrated that $\mathrm{A} / \mathrm{I}$ self-discrepancies were 
substantially stable; in addition, they were associated with emotional distress and memories with dysphoric contents from childhood.

One of the most robust findings related to SDT is the association between A/I self-discrepancies and depressive symptoms, after controlling for actual selfperceptions, in non-clinical and in clinical adult samples as well as in experimental and non-experimental studies (Boldero, Moretti, Bell, \& Francis, 2005; Hardin \& Lakin, 2009; Higgins, 1987, 1989; Wasylkiw, Fabrigar, Rainboth, Reid, \& Steen, 2010). The association between A/I self-discrepancies and depression-like states has been found in young children and adolescents as well. Stevens, Lovejoy, and Pittman (2014) found that A/I self-discrepancies accounted for depressive levels in $5^{\text {th }}$ grade children, after controlling for actual self-ratings, although the association between self-discrepancies and depression was stronger in $8^{\text {th }}$ graders. In addition, results showed gender differences, with A/I self-discrepancies significantly predicting depressive levels in girls, but not in boys. Similarly, Moretti and Wiebe (1999) reported sex differences in adolescence: Parental standards accounted for internalizing problems in girls but not in boys. These findings are in accordance with literature on gender differences in socialization processes (Cross \& Madson, 1997) and they indicate that socialization practices encourage daughters especially to meet others' standpoints (Moretti \& Higgins, 1999).

A/I self-discrepancies not only have emotional consequences, but they also represent emotionally significant standards for self-evaluations and have a significant impact on several psychological well-being domains thereby (Heindrich, 1999). Specifically, literature has consistently demonstrated that A/I self-discrepancies are correlated with self-esteem, in younger as well as older individuals. Moretti and Higgins (1990) reported that A/I self-discrepancies negatively correlated with the Rosenberg self-esteem scores, in university students. Their results also evidenced that self-discrepancies were associated with self-esteem levels when actual selfviews were statistically taken under control, but only if the discrepancies had been assessed ideographically rather than nomothetically. Ferguson, Hafen, and Laursen (2010) investigated the effects of $A / I$ discrepancies in adolescents attending $7^{\text {th }}$ to $11^{\text {th }}$ school grades and focused on both discrepancies favoring ideal self-views and those favoring actual self-views. Results from their study showed that discrepancies were modestly but significantly associated with depressive symptoms and low selfesteem, in distinct domain of the self-system, with stronger correlations among older adolescents.

Self-discrepancies have also been demonstrated to represent temporal antecedents of depressive conditions. In young adolescents, however, a two-year longitudinal study evidenced a bidirectional association between depression and poorer self-perceived competences relative to appraisals of significant others (Hoffman, Cole, Martin, Tram, \& Seroczynski, 2000). As to links between selfesteem and self-discrepancies, they have been investigated concurrently only. It thus remains empirically unexplored the direction of the association between self-esteem 
and A/I self-discrepancies. Generally, self-esteem has been basically conceptualized as the outcome of perceived discrepancies between how an individual believes s/he actually is and his/her ideal self (Rosenberg, 1979). As such, self-esteem has been demonstrated to predict depressive symptoms from adolescence to adulthood (Steiger, Allemand, Robins, \& Fend, 2014). Developmentally, Marsh, Craven, and Debus (1991) demonstrated that global self-esteem precedes rather than follows domain-specific evaluations in young children. Thus, young children appraise themselves in terms of good and bad. It is only later, from middle to late childhood, that boys and girls gradually develop the ability to compare themselves with others and take into account feedback from significant others, when they evaluate themselves (Harter, 2006). Children generally appraise themselves positively, reporting relatively high self-esteem levels, but the stability of their self-esteem ratings is low to moderate (Robins \& Trzesniewski, 2005). In brief, developmental trajectories of self-esteem and self-discrepancies are not parallel, although they both depend on cognitive as well as social competences that children acquire progressively. In fact, in late childhood, boys and girls can evaluate themselves in terms of self-worth at both global and domain-specific levels. Conversely, it is only from early adolescence on that conflicting self-representations become relevant in the self-system. It remains thus to be explored the direction of the association between self-esteem and self-discrepancies in late childhood, that is, years of transition, during which aspects of the self-system are rapidly changing. In our study, we explored such an association in $4^{\text {th }}$ and $5^{\text {th }}$ graders, across a 4-month period.

Meeting rather than failing parental standards is especially salient in childhood. In fact, significant adults provide children feedback on the presence or absence of positive outcomes by typically rewarding children with pride and affection, when they fulfill adults' ideal standards (Higgins, 1989; Moretti \& Higgins, 1999). To our knowledge, however, no systematical investigation on the effect of parents' feedback on children's self-discrepancies has been conducted yet. Parents influence their children's development in several ways, among which contingent behavioral and emotional responses to their children's behaviors in everyday interactions (Morris, Sick, Steinberg, Myers, \& Robinson, 2007). In the current study, we took into account two possible ways by which parents provide feedback to their children: Emotional reactions towards their children and perceived causes of discrepancies between children's actual behaviors and adults' hopes and desires. Parental distress and negative reactions predict more difficulties in their children's social functioning and favor the development of more negative self-views, from middle to late childhood (Eisenberg, Fabes, Shepart, Guthrie, Murphy, \& Reiser, 1999; Young, Lennie, \& Minnis, 2011). Causal attributions of unsuccessful events favor the development of helplessness, when stable, uncontrollable, and internal to person causes are identified such as abilities and dispositions (Dweck, 2000; Weiner, 1990). For the present study, we hypothesized that children report higher A/I selfdiscrepancies, when their parents refer more negative feelings towards their children and attribute them the causes of unfulfilled ideal behaviors. We also expected girls 
to be more sensitive than boys to parental feedback, because parents encourage girls more than boys in developing prosocial behaviors and sensitivity to the feelings of others (Cross \& Madson, 1997; Di Blas, 2007).

In brief, our two wave study was aimed at exploring how children's selfdiscrepancies are associated across time with children's self-esteem and with their parents' emotional reactions and explanations of their children's behavioral discrepancies.

\section{Method}

\section{Participants}

At the first measurement occasion, the present study involved 261 children (128 boys and 133 girls) who were attending $4^{\text {th }}(N=123)$ or $5^{\text {th }}(N=138)$ grades of elementary schools. They were aged between 7 to 11 years $(M=9.7, S D=0.7)$. Thirtysix fathers $(M=44.8$ years, $S D=5.5)$ and 168 mothers $(M=40.4$ years, $S D=5.1)$ also took part in the study.

Four months later, 96 of the children ( 37 per cent of the initial sample; 53 per cent boys) and 96 parents (52 mothers) participated in the study and provided valid reports.

\section{Measures and Procedure}

Self-Discrepancies Questionnaire for Children (S-DQC). For the present study, we developed a questionnaire aimed at assessing actual/ideal self-discrepancies in 8to 11-year old children. We initially generated 7 items for each of the Five Factor Model (FFM) domains of personality for children (Mervielde \& De Fruyt, 2002). After reading a sentence (e.g., I wish I got along with everybody), children were asked first to decide whether they wished they behaved or felt like described in the sentence, then to mark the best option for them among the following: "not interested to behave like that (we later coded as 1), "I am fine as I am" (coded as 1), "I wish a bit I behaved or felt like that" (coded as 2), "I wish a lot I behaved or felt like that" (coded as 3); a score of 1 indicated no discrepancy, higher scores indicated increasing self-discrepancy levels.

Test Multidimensionale dell'Autostima (TMA). TMA is the Italian version of the Multidimensional Self-Concept Scale (Bracken, 1992). TMA is a self-report questionnaire which assesses self-views in children, in six different domains; each domain evaluates how children gain information about themselves (personal and other perspectives) and how they evaluate themselves. As such, TMA represents a multidimensional measure of self-esteem (Bracken, 1996). For the present study, we selected a subset of items aimed at assessing self-views in terms of self-acceptance 
and self-worth especially. In addition, we focused our attention on the following domains: Social domain, aimed at assessing how a child feels about him/herself in relations to peers, whether s/he feels accepted and liked; Competence domain, which assesses whether a child feels appreciated, capable, and proud of him/herself within a school context or in relation to achievement; Family domain, how s/he feels when in family, supported, happy, and beloved; Affect domain, evaluating how a child feels s/he is good, satisfied with him/herself, and has worth. Children rated their agreement level with each item on a 4-point scale, ranging from $1=$ not all true for $m e$, to $4=a b s o l u t e l y$ true for me. For the present study, we selected 10 items for each domain and avoided presenting items highly similar in content. At the first measurement occasion (T1), Cronbach's alpha values ranged from .75 (Affect) to .79 (Family), and inter-scale correlations ranged from .33 to .60. Four-month test-retest correlations ranged from .44 (Affect) to .59 (Family). TMA scales did not correlate with children's age or sex.

Strengths and Difficulties Questionnaire (SQD-Ita). SDQ is a short behavioral screening questionnaire, designed to be applicable to 4- to 16-year old children and adolescents. SDQ assesses strengths and difficulties related to the following domains of clinical interest in personality development: Hyperactivity scale, Conduct Problems scale, Emotional Symptoms scale, Peer Problems scale, and Prosocial scale (Goodman, 1997). Each scale presents 5 items. We administered children the Italian version of SDQ (self-report format). We however did not present children the 5 items tapping prosocial behaviors. In addition, we partially changed instructions and asked children to report on their own behaviors along a 4- instead of 3-point Likert scale (from 1=never, to 4=many times) in order to enhance scores variability. Cronbach's alpha was .76 for the Total Difficulties scale (at T1) and test-retest correlation was .59 ( $p \leq .001, N=86)$.

Profile of Mood States (POMS). POMS is a self-report measure consisting of 65 adjectives selected in order to assess how people feel in terms of Tension-Anxiety (TA), Depression-Dejection (DD), Anxiety-Hostility (AH), Fatigue-Inertia (FI), Vigor-Activity (VA), and Confusion-Bewilderment (CB) (McNair, Lorr, \& Droppleman, 1981). For the present study, parents were asked to rate their feelings towards their children, in the last six months, along a 5-poin Likert scale. Alphas ranged from $.69(\mathrm{CB})$ to $.87(\mathrm{DD})$, at $\mathrm{T} 1$. Test-retest correlations $(N=51)$ ranged from $.29(p \leq .05, \mathrm{FI})$ to $.43(p \leq .01, \mathrm{TA})$. POMS scores correlated neither with parents' sex nor with parents' age; only VA scores were slightly higher for younger parents $(r=-$ $.21, p \leq .01)$. Moreover, parents reported to feel lower VA levels $(r=-.26, p \leq .001)$ and higher $\mathrm{AH}(r=-.28, p \leq .001)$, FI $(r=-.25, p \leq .001)$, and TA $(r=-.20, p \leq .01)$ levels for younger children.

Causal Ascriptions of Children's Behaviors Questionnaire (CACB). This questionnaire was developed for the present study, in order to evaluate parents' causal attributions of their children's behaviors. We generated 33 sentences by combining 
the main domains of causal perceptions, i.e., locus of control (further distinguishing between internal to parent or to child vs. external to child), controllability, and stability (Weiner, 1990). Parents were asked to rate whether their perceived actual/ideal discrepancies in their child's behavior depend on the cause described in each sentence (e.g., I am not capable of handling him/her), by using a 5-point scale, ranging from $1=$ never or rarely, to $5=\mathrm{o}$ ften or always.

\section{Results}

Preliminary Analyses

Component structure of the Self-Discrepancies Questionnaire for Children. When we performed principal component analysis on the set of 261 self-ratings that children provided at $\mathrm{T} 1$, the first eigenvalues before rotation $(8.7,1.9,1.5$, and 1.3) strongly suggested a General A/I Self-discrepancy component, which accounted for the 30 per cent of the total variance. A robust and interpretable component solution however also emerged when 29 items were reduced into 4 varimax rotated components, which accounted for the 46.0 per cent of the total variance; the remaining 6 items did present factor loadings lower than .30 on a 4-component solution and were excluded from further analyses. Table 1 presents the 4-component solution. The first rotated component collected items dealing with actual/ideal discrepancies in the domain of intellectual capabilities; we labeled this domain $A / I$ Self-discrepancies in Intellect. Items representing emotional discrepancies loaded on the second component and we labeled it A/I Self-discrepancies in Emotional Stability. Items representing facets of Benevolence and Conscientiousness and mostly indicating behavioral and cognitive control loaded on the third component and we labeled it A/I Self-discrepancies in Impulse Control. Lastly, items loading on the fourth component were mixed, because they originally represented different FFM domains, nevertheless their content suggested discrepancies dealing with acceptance and getting along with peers; thus, we labeled this component A/I Self-discrepancies in Sociability. Cronbach's alphas for the scales were .83 for Intellect (7 items), .82 for Emotional Stability (10 items), .80 for Impulse Control (7 items), and .66 for Sociability (5 items). Test-retest stability coefficients for principal component scores $(N=96)$ were moderate to high in size and ranged from .45 (A/I Self-discrepancies in Impulse Control) to .64 (A/I General Self-discrepancy Component); children's age did not moderate stability coefficients. Component scores in self-discrepancies domains did not correlate with children's age or sex, with one exception only, girls reported higher self-discrepancy levels in Sociability $(r=.20, p \leq .05)$. 
Table 1. Principal Component Solution for the Self-Discrepancies Questionnaire for Children (S-DQC), after Varimax Rotation

\begin{tabular}{|c|c|c|c|c|c|}
\hline \multirow{3}{*}{$\begin{array}{l}\text { FFM } \\
\text { I wish ... }\end{array}$} & \multirow[b]{3}{*}{ Domain } & \multicolumn{4}{|c|}{ Component } \\
\hline & & 1 & 2 & 3 & 4 \\
\hline & & Intellect & $\begin{array}{l}\text { Emotional } \\
\text { Stability }\end{array}$ & $\begin{array}{l}\text { Impulse } \\
\text { Control }\end{array}$ & Sociability \\
\hline ... I could easily learn things I have to study & IMA & .71 & & & \\
\hline $\begin{array}{l}\text {... I could quickly understand what my teacher } \\
\text { explain to me in classroom }\end{array}$ & IMA & .67 & & & \\
\hline ... I had a good memory & IMA & .64 & & & \\
\hline ... I easily learnt new things or subjects & IMA & .62 & & & \\
\hline $\begin{array}{l}\text {... I could try harder when necessary and be } \\
\text { successful in what I do }\end{array}$ & $\mathrm{CON}$ & .61 & .37 & & \\
\hline ... I could answer my teacher correctly & IMA & .60 & & & \\
\hline $\begin{array}{l}\ldots \text { I were capable of concentrating on what I } \\
\text { have to learn during class hours }\end{array}$ & $\mathrm{CON}$ & .56 & & .33 & \\
\hline ... I did not easily feel offended & $\mathrm{BEN}$ & & .66 & & \\
\hline $\begin{array}{l}\text {... I were not afraid of making mistakes or failing } \\
\text { when I want to do something }\end{array}$ & EST & & .63 & & \\
\hline $\begin{array}{l}\text {... I didn't feel anxious or worried even for small } \\
\text { things }\end{array}$ & EST & & .62 & & \\
\hline$\ldots$ I could avoid crying & EST & & .59 & & \\
\hline $\begin{array}{l}\text {... I could talk even in front of a lot of children, } \\
\text { without feeling embarrassed }\end{array}$ & EXT & & .57 & & \\
\hline ... I could avoid getting scared easily & EMS & & .55 & & \\
\hline $\begin{array}{l}\text {... I did not feel discouraged easily, when I can } \\
\text { not do something }\end{array}$ & EMS & & .51 & & \\
\hline ....I did not argue with other children & BEN & & .50 & .31 & \\
\hline ... I did not feel sad & EMS & & .46 & & \\
\hline ... I won when I compete & EXT & & .42 & & \\
\hline $\begin{array}{l}\text {... I could do my homework without getting } \\
\text { distracted easily }\end{array}$ & $\mathrm{CON}$ & .32 & & .65 & \\
\hline ... I didn't tell lies & $\mathrm{BEN}$ & & & .61 & \\
\hline ... I could do my homework carefully & $\mathrm{CON}$ & .46 & & .58 & \\
\hline $\begin{array}{l}\text {... I could feel pleased when I share my things } \\
\text { with other children }\end{array}$ & BEN & & & .56 & \\
\hline ... I kept my room tidy & $\mathrm{CON}$ & & & .55 & \\
\hline $\begin{array}{l}\ldots \text { I were capable of comforting a friend when } \\
\mathrm{s} / \text { he is sad }\end{array}$ & $\mathrm{BEN}$ & & & .55 & \\
\hline $\begin{array}{l}\text {... I finished my homework without getting } \\
\text { distracted }\end{array}$ & $\mathrm{CON}$ & .44 & & .54 & \\
\hline ... I understood other children's feelings & BEN & & & & .65 \\
\hline ... I could invent new and fun games & IMA & & & & 60 \\
\hline $\begin{array}{l}\text {... I were the one who decides what to do or play, } \\
\text { when I am with other children }\end{array}$ & EXT & & & & .56 \\
\hline ... I had got lots of imagination & IMA & & & & .49 \\
\hline ... I made friends easily & EXT & & & .35 & .36 \\
\hline Percentage of accounted variance & & 13.5 & 13.5 & 11.4 & 7.6 \\
\hline
\end{tabular}

Note. Mean values replaced missing values ( $<3$ per cent). Factor loadings $\geq .30$ are reported. Five Factor Model (FFM) Domains: EXT = Extraversion, $\mathrm{BEN}=$ Benevolence, $\mathrm{CON}=$ Conscientiousness, EST = Emotional Stability, IMA = Imagination. 
Component structure of the Causal Ascriptions of Children's Behaviors questionnaire $(C A C B)$. When principal component analysis was performed on the data set collected at T1, the first 6 eigenvalues $(10.6,2.24,1.96,1.63,1.50$, and 1.19) suggested exploring up to 5 components; the five component solution however was not interpretable. Table 2 presents the 4 -varimax rotated component solution which accounted for the 49.5 per cent of the total variance. The first component collected items attributing causes of discrepancies in children's actual/ideal behaviors that combined stability and child's internal locus; we therefore labeled it Stable and internal-to-child causes. Items representing unstable and uncontrollable causes loaded on the second component, Unstable and uncontrollable causes. The third component collected external causes of discrepancies in children's actual/ideal behaviors, External causes. Stable causes due to parents' internal locus loaded the fourth component, which we labeled Stable and internal-to-parent causes. Cronbach's alphas for the scales ranged from .75 (Stable and internal-to-parent causes) to .90 (Stable and internal-to-child causes), at T1. Parents attributed to external causes $\mathrm{A} / \mathrm{I}$ behavioral discrepancies in their boys more than they did for their girls $(r=-.22, p \leq .01)$; in addition, fathers attributed to themselves causes of discrepancies more than did mothers $(r=-.18, p \leq .01)$, at T1.

Table 2. Principal Component Solution for the Causal Ascriptions of Children's Behaviors Questionnaire (CACB), after Varimax Rotation

\begin{tabular}{|c|c|c|c|c|}
\hline & \multicolumn{4}{|c|}{ Component } \\
\hline & 1 & 2 & 3 & 4 \\
\hline \multicolumn{5}{|l|}{ When my child acts differently from how I would ideally like, this happens because } \\
\hline s/he can't control his/her behavior enough & .72 & & & \\
\hline disobeying orders and breaking rules comes natural to him/her & .69 & .34 & & \\
\hline some situations make him/her difficult to take under control & .68 & .31 & & \\
\hline $\mathrm{s} / \mathrm{he}$ is a difficult child & .66 & & & \\
\hline s/he challenges me quickly & .65 & & & \\
\hline $\mathrm{s} / \mathrm{he}$ is in a bad mood & & .65 & & \\
\hline I am in a bad mood & & .64 & & \\
\hline I feel tired & & .63 & & \\
\hline I feel impatient & & .61 & & \\
\hline $\mathrm{s} / \mathrm{he}$ is tired & & .52 & .35 & \\
\hline other people make him/her disobeying & & & .56 & \\
\hline no special reasons, it happens occasionally & & .34 & .54 & \\
\hline it happens by chance, just coincidences & & & .46 & \\
\hline behavioral models around him/her are bad & & & .38 & \\
\hline $\begin{array}{l}\text { other people are not clear enough and s/he doesn't understand what s/he is } \\
\text { expected to do }\end{array}$ & .33 & & .34 & \\
\hline I do not try hard enough to take care of him/her as I should & & & & .84 \\
\hline I can't take care of him/her enough & & & & .80 \\
\hline I do not try enough to give him/her any rule & & & & .54 \\
\hline I am not capable of taking care of him/her as I should & .33 & & & .51 \\
\hline I do not invest on him/her all the energies s/he needs & & & & .43 \\
\hline Percentage of accounted variance & 15.9 & 11.6 & 11.5 & 10.4 \\
\hline
\end{tabular}

Note. Factor loadings $\geq .30$ are reported. Labels of the principal components: 1 . Stable and internal-tochild causes; 2. Unstable and uncontrollable causes; 3 . External causes; 4. Stable and internal-to-parent causes. 


\section{Concurrent Associations}

Table 3 presents concurrent simple correlations observed among children's selfratings and between children's and parents' ratings. Children's intra-personal correlations revealed some modest but significant associations between A/I selfdiscrepancies and self-esteem and behavioural difficulties. They showed that higher self-reported A/I discrepancies are associated with more negative self-views. In fact, both lower TMA and higher SDQ Total Difficulties scale scores correlated with higher self-reported discrepancies levels. Simple correlations between SDQ and TMA ranged from -.39 (TMA Family domain and SDQ Difficulties total scores, $p \leq .001$ ) to .70 (TMA total scores and SDQ Difficulties total scores, $p \leq .001$ ).

The concurrent correlations between SDs and self-esteem levels were further investigated via regression analysis, in order to control for self-reported actual difficulties on SDQ. Specifically, when predicting domains in self-discrepancies we first entered SDQ scores and then TMA variables, in the regression analysis; similarly, when predicting TMA, we first entered SDQ and then component scores in A/I self-discrepancies. Table 4 presents results from regression analysis and they revealed that the TMA Competence accounted for a substantial unique variance proportion of self-reported discrepancies in the domain of intellectual capabilities (Table 4, upper part), and vice versa (Table 4, lower part). Similarly, the TMA Affect scale predicted a significant, though very modest, variance proportion of selfdiscrepancies in the Impulse Control domain, and vice versa. Lastly, we regressed SDQ Total Difficulties scores on self-discrepancies and TMA scales. Results showed that higher discrepancies levels in Emotional Stability contributed to predict higher self-reported difficulties $(s r=.10, p \leq .05)$, after controlling for TMA scales which accounted for the 50 per cent of the total variance of the outcome.

When intra-personal associations for parents were inspected, regression analysis showed that POMS TA accounted for the 8.3 per cent of the total variance of Stable and internal-to-child causes component: The more parents attributed to children's internal causes their undesirable behaviors, the higher the tension levels parents referred they felt towards their children. 
Table 3. Concurrent Correlations between Children's Self-Ratings and Ratings Provided by Parents

\begin{tabular}{|c|c|c|c|c|c|c|c|c|c|}
\hline \multirow[b]{2}{*}{$T M A$} & \multicolumn{5}{|c|}{$\begin{array}{c}\text { Intrapersonal correlations: } \\
\text { A/I Self-discrepancies } \\
\text { Components }\end{array}$} & \multicolumn{4}{|c|}{$\begin{array}{l}\text { Interpersonal } \\
\text { correlations: } \\
\text { CACB } \\
\end{array}$} \\
\hline & Gen & Int & Emo & Imp & Soc & Child & Unstable & External & Parent \\
\hline $\begin{array}{l}\text { Social } \\
\text { domain }\end{array}$ & $-.31^{* *}$ & $-.29^{* *}$ & $-.20^{* *}$ & -.04 & -.04 & $-.25^{* *}$ & -.03 & -.02 & -.10 \\
\hline $\begin{array}{l}\text { Affect } \\
\text { domain }\end{array}$ & $-.19^{*}$ & $-.21^{*}$ & $-.20^{*}$ & .06 & .04 & $-.22^{*}$ & .00 & .00 & -.05 \\
\hline $\begin{array}{l}\text { Competence } \\
\text { domain }\end{array}$ & $-.27^{* *}$ & $-.38^{* *}$ & -.07 & -.05 & .02 & -.11 & .06 & -.02 & -.13 \\
\hline $\begin{array}{l}\text { Family } \\
\text { domain }\end{array}$ & -.06 & $-.16^{*}$ & .01 & .08 & -.05 & $-.22^{*}$ & .05 & .02 & $-.17^{*}$ \\
\hline $\begin{array}{l}\text { TMA total } \\
\text { score }\end{array}$ & $-.27^{* *}$ & $-.34^{* *}$ & $-.15^{*}$ & .01 & -.01 & $-.26^{* *}$ & .02 & -.01 & -.14 \\
\hline $\begin{array}{l}\text { SDQ total } \\
\text { score }\end{array}$ & $.31^{* *}$ & $.25^{* *}$ & $.22^{* *}$ & .08 & .04 & $.33^{* *}$ & .05 & .14 & .03 \\
\hline
\end{tabular}

Note. A/I self-discrepancies $(N=261) ;$ Gen $=$ General component; Int = Intellect component; Emo = Emotional Stability component; Imp = Impulse Control component; Soc = Sociability component; Causal Ascriptions of Children's Behaviors questionnaire (CACB, $N=195)$; Child = Stable and internalto-child causes; Unstable $=$ Unstable and uncontrollable causes; Ext $=$ External causes; Parent $=$ Stable and internal-to-parent causes.

${ }^{*} p \leq .01 ;{ }^{* *} p \leq .001$.

Table 4. Predicting A/I Self-Discrepancies (SD) from TMA Domains and Vice Versa, after Controlling for Actual Behavioral Difficulties via SDQ: Concurrent Associations

\begin{tabular}{lcclc}
\hline Predicting A/I Self-discrepancies from TMA domains & \multicolumn{1}{c}{ Predictor } & $s r$ \\
\cline { 2 - 6 } & Step & $R_{\text {change }}^{2}$ & \multicolumn{1}{c}{ (10 } \\
\hline A/I SD: General component & 1 & $.10^{* * *}$ & SDQ Difficulties & $.15^{* *}$ \\
& 2 & $.02^{*}$ & TMA Social & $-.14^{*}$ \\
\hline A/I SD in Intellect & 1 & $.06^{* * *}$ & SDQ Difficulties & .04 \\
& 2 & $.09^{* * *}$ & TMA Competence & $-.30^{* * *}$ \\
\hline A/I SD in Impulse Control & 1 & .01 & SDQ Difficulties & $.13^{*}$ \\
& 2 & .02 & TMA Affect & $-.13^{*}$ \\
\hline
\end{tabular}


Table 4. - Continued

\begin{tabular}{|c|c|c|c|c|}
\hline \multicolumn{5}{|c|}{ Predicting TMA domains from A/I Self-discrepancies } \\
\hline & Step & $R_{\text {change }}^{2}$ & Predictor & $s r$ \\
\hline \multirow[t]{2}{*}{ TMA: Total score } & 1 & $.48^{* * * *}$ & SDQ Difficulties & $-.68^{* * * *}$ \\
\hline & 2 & $.03^{* * *}$ & $\mathrm{~A} / \mathrm{I}$ SD in Intellect & $-.17^{* * * *}$ \\
\hline \multirow[t]{2}{*}{ TMA Affect domain } & 2 & $.33^{* * *}$ & SDQ Difficulties & $-.59^{* * * *}$ \\
\hline & 3 & $.01^{*}$ & A/I SD in Impulse Control & $-.10^{*}$ \\
\hline \multirow{2}{*}{ TMA Competence domain } & 2 & $.32^{* * *}$ & SDQ Difficulties & $-.48^{* * * *}$ \\
\hline & 3 & $.06^{* * *}$ & $\mathrm{~A} / \mathrm{I} \mathrm{SD}$ in Intellect & $-.25^{* * *}$ \\
\hline \multirow[t]{2}{*}{ TMA Social domain } & 2 & $.40^{* * *}$ & SDQ Difficulties & $-.58^{* * * *}$ \\
\hline & 3 & $.02^{* *}$ & A/I SD: Intellect & $-.14^{* *}$ \\
\hline
\end{tabular}

Note. For TMA domains increases in $R^{2}$ are reported after estimating a given TMA domain from the remaining TMA domains, at step 1. A/I SD = Actual/Ideal Self-discrepancies $(N=261) ; \mathrm{SDQ}=$ Strengths and Difficulties Questionnaire (total score); TMA = Multidimensional Self-Concept Scale ${ }^{*} p \leq .05 ;{ }^{* *} p \leq .01 ;{ }^{* * *} p \leq .001$.

When inter-personal child/parent associations were inspected, simple correlations (Table 3) showed that the more the parents ascribed to children's internal locus and stable characteristics the more the children referred behavioral difficulties on SDQ and lower self-esteem levels on TMA. More in detail, regression analyses revealed that the lower the children's self-esteem in the Family domain, the more parents attributed to children's internal causes their undesirable behaviors, with TMA Family accounting for 5.5 per cent of variance $(p \leq .001)$, after partialling POMS TA. Some significant $(p \leq .05)$, although modest, inter-personal simple correlations were observed between A/I self-discrepancies components and POMS scores as well. Regression analysis for moderating effects however showed that children's sex moderated the POMS / SDs associations which were generally significant for girls, but not for boys. Specifically, a significant interaction effect emerged between sex and POMS-DA $\left(R_{\text {change }}^{2}=.03, p \leq .05\right)$ and between sex and POMS-AR $\left(R_{\text {change }}^{2}=.02\right.$, $p \leq .05)$ in predicting scores in the General component from A/I self-discrepancies. Furthermore, in girls only POMS-DA and POMS-VA accounted for additional variance $\left(R_{\text {change }}^{2}=.08, p \leq .01\right.$ and $R_{\text {change }}^{2}=.04, p \leq .05$, respectively) of the A/I General component, when SDQ and the TMA Social domain were taken under control. Similarly, in girls only POMS-CS contribute to predict for a significant additional variance $\left(R_{\text {change }}^{2}=.09, p \leq .01\right)$ of A/I SD Intellect, after partialling SDQ and the TMA Competence scores.

\section{Temporal Antecedents and Correlated Changes Across Time}

Cross-lagged pattern associations revealed temporal antecedents and correlated changes of children's self-ratings. Specifically, we predicted the T2 outcome entering the $\mathrm{T} 1$ outcome together with the T1 predictors, in order to systematically control for the indirect effect of the $\mathrm{T} 1$ antecedents on the dependent variable via the $\mathrm{T} 1$ 
outcome. Hence, the semi-partial correlation between T2 outcome and T1 antecedent represented the unique impact of the $\mathrm{T} 1$ antecedent on the $\mathrm{T} 2$ outcome variability, that is, the effect of the $\mathrm{T} 1$ antecedent on change levels in the dependent variable from $\mathrm{T} 1$ to $\mathrm{T} 2$. When in the regression model, the $\mathrm{T} 2$ explanatory variable was further added, the partial correlation between $\mathrm{T} 2$ outcome and $\mathrm{T} 2$ predictor represented the association between changes in the two variables across time, controlling for all the investigated antecedents (Asendorpf \& Van Aken, 2003).

Table 5 presents results emerged from such an analytical approach, when children's self-ratings were inspected. The results showed that initial TMA scores predicted changes in self-discrepancies from $\mathrm{T} 1$ to $\mathrm{T} 2$, after controlling for $\mathrm{T} 1$ actual behavioral difficulties. Specifically, lower TMA Competence domain scores predicted increases in A/I self-discrepancies in Intellect, four months later. In addition, further analyses revealed that changes in A/I self-discrepancies in Intellect negatively correlated with changes in TMA Competence, that is, increases in A/I self-discrepancies in the domain of intellectual capabilities correlated with decreases in children's self-esteem in relation to school context and achievement ( $p r=-.18$, $p \leq .05$ ), after controlling for T1 SDQ as well. Results in Table 5 also show that lower TMA Social domain scores anticipated increases in A/I self-discrepancies in Impulse Control, that is, children who initially referred to feel less liked and accepted by their peers increased their referred levels of discrepancy between how they believe they actually voluntary share their things and focus their attention on homework and they wish they could do, four months later. Changes in these two variables were negatively correlated across time ( $p r=-.30, p \leq .01)$. Lastly, A/I self-discrepancies in the domain of interpersonal relationships increased when children initially referred to feel less accepted and beloved in their family; no correlated changes emerged.

Table 5. Predicting A/I Self-Discrepancies from SDQ and TMA Domains: Temporal Antecedents

\begin{tabular}{|c|c|c|c|c|}
\hline \multicolumn{5}{|c|}{ Predicting A/I Self-discrepancies from TMA domains } \\
\hline Dependent Variable at T2 & Step & $R_{\text {change }}^{2}$ & Predictor at $\mathrm{T} 1$ & $s r$ \\
\hline \multirow[t]{2}{*}{ A/I SD: General component } & 1 & $.41^{* * * *}$ & A/I SD: General component & $.59^{* * * *}$ \\
\hline & 2 & $.04^{*}$ & SDQ Difficulties & $.20^{*}$ \\
\hline \multirow[t]{3}{*}{$\mathrm{A} / \mathrm{I} \mathrm{SD}$ in Intellect } & 1 & $.28^{* * * *}$ & $\mathrm{~A} / \mathrm{I}$ SD in Intellect & $.41^{* * * *}$ \\
\hline & 2 & .02 & SDQ Difficulties & .04 \\
\hline & 3 & $.03^{*}$ & TMA Competence & $-.18^{*}$ \\
\hline \multirow[t]{3}{*}{$\mathrm{A} / \mathrm{I}$ SD in Impulse Control } & 1 & $.20^{* * * *}$ & A/I SD in Impulse Control & $.45^{* * *}$ \\
\hline & 2 & .02 & SDQ Difficulties & -.02 \\
\hline & 3 & $.04^{*}$ & TMA Social & $-.20^{*}$ \\
\hline \multirow[t]{3}{*}{$\mathrm{A} / \mathrm{I}$ SD in Sociability } & 1 & $.26^{* * * *}$ & A/I SD in Sociability & $.51^{* * * *}$ \\
\hline & 2 & .01 & SDQ Difficulties & .05 \\
\hline & 3 & $.04^{*}$ & TMA Family & $-.20^{*}$ \\
\hline
\end{tabular}

Note. Semipartial correlations for the final regression model are reported. $N=90$ to $96 . \mathrm{A} / \mathrm{I} \mathrm{SD}=$ Actual/Ideal Self-discrepancies; SDQ = Strengths and Difficulties Questionnaire (total score); TMA = Multidimensional Self-Concept Scale

${ }^{*} p \leq .05 ;{ }^{* *} p \leq .01 ;{ }^{* * *} p \leq .001$. 
When we inspected whether initial A/I self-discrepancies accounted for change in TMA scores four months later, we did not find any significant predictor $(p \leq .05)$. In brief, results revealed that self-discrepancies were not temporal antecedents of changes in children's self-worth levels. Neither TMA scales or self-discrepancies domains predicted changes in SDQ difficulties.

When inter-personal associations across time were analysed, sex differences emerged which were consistent with results observed for concurrent associations. In fact, POMS-DA predicted increases in the A/I SD General component scores at T2 $\left(R_{\text {change }}^{2} .11, p \leq .05\right)$, after controlling for initial scores in the general component and SDQ (Table 5), in girls only $(N=23)$. POMS-DA accounted for changes in discrepancies in the Intellect domain, beyond predictors reported in Table 5, in girls but not boys. In addition, results from inter-personal data showed that parents' causal ascriptions were temporal antecedents of changes in children's A/I self-discrepancies in intellectual capabilities and in TMA Capabilities. In fact, T1 higher scores on Stable and internal-to-parent causes significantly predicted increases in children's self-reported discrepancies in the domain of intellectual capabilities $(s r=.24, p \leq .05)$, after controlling for TMA Competence $(s r=-.24, p \leq .05)$ as well. As to TMA Competence, results indicated that the less the parents attributed to stable and internal-to child causes $(s r=-.30, p \leq .01)$ and to internal-to parent causes $(s r=-.24$, $p \leq .05$ ) perceived discrepancies between their children's actual and desired behaviors, the more their children's self-esteem level in TMA Competence increased across time, with the two attributional styles accounting for $R_{\text {change }}^{2}=.15$ ( $\left.p \leq .001\right)$, after controlling for children's self ratings on self-discrepancies and TMA at the first measurement occasion. These results also demonstrated that self-esteem uniquely accounted for changes in self-discrepancies, but not vice versa, when parental causal attributions were taken under control.

\section{Discussion}

The present study was mainly aimed at exploring possible temporal antecedents of self-discrepancies in late childhood. To this aim, $4^{\text {th }}$ and $5^{\text {th }}$ grade children and their parents were involved and asked to take part in a two-wave study, with an interval of 4 months between the two assessment occasions. In accordance with literature, self-esteem and self-discrepancies were concurrently associated in our sample of children (Moretti \& Higgins, 1990). However, the main finding of our study is that children's self-esteem predicted changes in self-discrepancies, but not vice versa, after controlling for actual self-ratings, in both boys and girls. This finding contradicts the theoretical impact of self-discrepancies on self-esteem (Harter, 2006; Moretti \& Higgins, 1990). Our finding may depend on the developmental trajectories of the two psychological constructs. Both self-esteem and self-discrepancies are moderately stable across these ages and our results further supported that change tends to prevail on the continuity of these variables in late childhood (Robins \& 
Trzesniewski, 2005). Nevertheless, children appraise themselves in terms of good vs. bad since preschool years and they are increasingly capable of evaluating their own worth in different domains across elementary school years (Harter, 1999; Marsh et al., 1991). On the contrary, children start developing self-views and self-appraisals around incongruencies between 9 to 12 years, with a significant increase in terms of salience and complexity between 12 to 14 years (Oosterwegel \& Oppenheimer, 2002). It is also around 13 years that the correlations between self-discrepancies and outcome variables become stronger (Stevens et al., 2014). We thus propose the hypothesis that children's self-worth initially affects the development of selfdiscrepancies, because self-esteem is more articulated than self-discrepancies are in late childhood. Further empirical data however are needed to deeply explore such a proposal: A longer time period should be inspected, with not less than three measurement occasions, in order to explore cascade effects across time, and young adolescents should also be included, in order to verify whether the direction of the association from self-esteem to discrepancies changes across these developmental ages.

The current study used a newly developed questionnaire to assess children's discrepancies nomothetically. The Self-discrepancies Questionnaire for Children has to be refined and further validated. Nevertheless, results indicate that children provided ratings on their self-discrepancies that yielded two conceptually coherent components - i.e., Intellect and Emotional Stability - and two further interpretable and reliable components. In addition, children reported on their self-discrepancies quite coherently across time. Intra-personal correlation patterns showed that selfdiscrepancy levels in the domains of Intellect and Emotional Stability were associated with lower self-esteem and higher SDQ behavioral difficulties, that is, more actual negative self-views, both concurrently and across time. The effect size of the associations here observed was comparable with levels reported in literature (Stevens et al., 2014). Overall, these findings suggest that $4^{\text {th }}$ and $5^{\text {th }}$ graders have already developed some fairly consistent self-representations around conflicting actual and ideal selves.

Remarkably, substantial child/parent correlations emerged as well. Despite the limits of the Self-discrepancies Questionnaire for Children, results of the present study revealed that girls were sensitive to feedback from their parents. In fact, girls reported increases in self-discrepancies when parents initially referred more negative feelings towards their children. Such a finding supports the relevance of emotional feedback that parents give to their children by rewarding them with love (Eisenberg et al., 1999; Moretti \& Higgins, 1999; Young et al., 2011). It also further demonstrates that socialization processes favor the development of interdependent self-representations in girls (Cross \& Madson, 1997), whose self-descriptions reveal higher levels of nurturance, when compared to boys, since elementary school years (Di Blas, Grassi, Luccio, \& Momentè, 2012). Child/parent substantial associations were also observed for TMA scores and stable and internal causes that parents 
attributed to discrepancies between their children's actual and ideal behaviors. The more parents initially evoked dispositional causes to explain behavioral incongruencies of their children's behaviors, the more their children's self-esteem levels decreased across fourth months. This finding supports the negative effect of causal attributions in terms of dispositions (Dweck, 2000; Weiner, 1990), regardless of whether the locus of dispositional causes is internal to the child or the parent.

The present study was developed with exploratory purposes. It presents several limits thereby. Methodologically, self-discrepancies should rather be assessed idiographically, in order to better understand how the self-system functions. In addition, self-discrepancies generally show stronger correlations with outcome variables, after controlling for actual self-representations, when self-discrepancies are assessed idiografically rather than nomothetically (Hardin \& Lakin, 2009; Moretti \& Higgins, 1990). It thus remains to explore how self-relevance of the different domains of self-discrepancies and self-esteem affects their associations in terms of both magnitude and direction, in late childhood. The questionnaire we here developed for assessing self-discrepancies in children has to be improved and crossvalidated. Developmentally, data from children between 8 to 14 years would help understanding the association between self-worth and self-discrepancies across these ages. A larger data sample would also allow exploring possible sex differences in developmental trajectories in these variables and their associations. More outcome variables should also be included such as depression, school achievement, peer relationships, parental support and parents' self-discrepancies, in order to better understand risk factors for the development of self-discrepancies and more vulnerable self-representations thereby. The present study offers some initial but encouraging findings.

\section{References}

Asendorpf, J.B., \& Van Aken, M.A.C. (2003). Personality-relationship transaction in adolescence: Core versus surface personality characteristics. Journal of Personality, 71, 629-666.

Boldero, J.M., Moretti, M.M., Bell, R.C., \& Francis, J.J. (2005). Self-discrepancies and negative affect: A primer on when to look for specificity, and how to find it. Australian Journal of Psychology, 57, 139-147.

Bracken, B.A. (1992). MSCS - Multidimensional Self-Concept Scale. Italian version, $R$. Mazzeo (ed), TMA Test di Valutazione dell'Autostima. Trento: Erickson.

Bracken, B.A. (1996). Handbook of self-concept. Wiley, New York.

Cross, S.E., \& Madson, L. (1997). Models of the self: Self-construals and gender. Psychological Bulletin, 122, 5-37. 
Di Blas, L. (2007). A circumplex model of interpersonal attributes in middle childhood. Journal of Personality, 75, 863-897.

Di Blas, L., Grassi, M., Luccio, R., \& Momentè, S. (2012). Assessing the interpersonal circumplex model in late childhood: The Interpersonal Behavior Questionnaire for Children. Assessment, 19, 421-441.

Dweck, C.S. (2000). Self-theories: Their role in motivation, personality and development. Philadelphia, PA: Taylor \& Francis.

Eisenberg, N., Fabes, R.A., Shepart, S.A., Guthrie, I.K., Murphy, B.C., \& Reiser, M. (1999). Parental reactions to children's negative emotions: Longitudinal relations to quality of children's social functioning. Child Development, 70, 513-534.

Ferguson, G.M., Hafen, C.A., \& Laursen, B. (2010). Adolescent psychological and academic adjustment as a function of discrepancies between actual and ideal self-perceptions. Journal of Youth and Adolescence, 39, 1485-1497.

Goodman, R. (1997). The strengths and difficulties questionnaire: A research note. Journal of Child Psychology and Psychiatry and Allied Disciplines, 38, 581-586.

Hardin, E.E., \& Lakin, J.L. (2009). The integrated self-discrepancy index: A reliable and valid measure of self-discrepancies. Journal of Personality Assessment, 91, 245-253.

Harter, S. (1999). The construction of the self. New York, NY, US: Guilford Press.

Harter, S. (2006). Developmental and individual differences perspectives on self-esteem. In D.K. Mroczek \& T.D. Little (Eds.), Handbook of personality development (pp. 311334). Mahwah, NJ: LEA.

Heindrich, S.M. (1999). Self-discrepancy across the life span. Journal of Adult Development, 6, 119-130.

Higgins, E.T. (1987). Self-discrepancy: A theory relating self and affect. Psychological Review, 94, 319-340.

Higgins, E.T. (1989). Continuities and discontinuities in self-regulatory and self-evaluative processes: A developmental theory relating self and affect. Journal of Personality, 57, 407-444.

Hoffman, K.B., Cole, D.A., Martin, J.M., Tram, J., \& Seroczynski, A.D. (2000). Are the discrepancies between self- and others' appraisals of competence predictive or reflective of depressive symptoms in children and adolescents: A longitudinal study, part II. Journal of Abnormal Psychology, 109, 651-662.

Marsh, H.W., Craven, R.G., \& Debus, R.L. (1991). Self-concepts of young children 5 to 8 years of age: Measurement and multidimensional structure. Journal of Educational Psychology, 83, 377-392.

McNair, D.M., Lorr, M., \& Droppleman, L.F. (1981). Manual for the profile of the mood states. Italian version, M. Farnè, A. Sebellico, D. Gnugnoli, A. Corallo (eds). Firenze: Organizzazioni Speciali. 
Mervielde, I., \& De Fruyt, F. (2002). Assessing children's traits with the Hierarchical Personality Inventory for Children. In B. De Raad \& M. Perugini (Eds.), Big Five assessment (pp. 129-146). Göttingen, Germany: Hogrefe \& Huber Publishers.

McDaniel, B.L., \& Grice, J.W. (2005). Measuring self-discrepancies on the Big Five personality traits with the repertory grid. Personal Construct Theory \& Practice, 2, 18 31.

Moretti, M.M., \& Higgins, E.T. (1990). Relating self-discrepancy to self-esteem: The contribution of discrepancy beyond actual self-ratings. Journal of Experimental Social Psychology, 26, 108-123.

Moretti, M.M., \& Higgins, E.T. (1999). Internal representations of others in self-regulation: A new look at a classic issue. Review of General Psychology, 3, 188-223.

Moretti, M.M., \& Wiebe, V.J. (1999). Self-discrepancy in adolescence: Own and parental standpoints on the self. Merrill-Palmer Quarterly, 4, 624-649.

Morris, A.S., Sick, J.S., Steinberg, L., Myers, S.S., \& Robinson, L.R. (2007). The role of the family context in the development of emotion regulation. Social Development, 16, 361388.

Oosterwegel, A., \& Oppenheimer, L. (2002). Jumping to awareness of conflict between self - representations and its relation to psychological well-being. International Journal of Behavioral Development, 26, 548-555.

Robins, R.W., \& Trzesniewski, K.H. (2005). Self-esteem development across the lifespan. Current Directions in Psychological Science, 14, 158-162.

Rosenberg, M. (1979). Conceiving the self. New York: Basic Books, Inc.

Steiger, A.E., Allemand, L.M., Robins, R.W., \& Fend, H.A. (2014). Low and decreasing selfesteem during adolescence predict adult depression two decades later. Journal of Personality and Social Psychology, 106, 325-338.

Stevens, E.N., Lovejoy, M.C., \& Pittman, L.D. (2014). Understanding the relationship between actual: Ideal discrepancies and depressive symptoms: A developmental examination. Journal of Adolescence, 37, 612-621.

Strauman, T.J. (1996). Stability within the self: A longitudinal study of the structural implications of self-discrepancy theory. Journal of Personality and Social Psychology, $71,1142-1153$.

Young, R., Lennie, S., \& Minnis, H. (2011). Children's perceptions of parental emotional neglect and control and psychopathology. Journal of Child Psychology and Psychiatry, $52,889-897$.

Wasylkiw, L., Fabrigar, L.R., Rainboth, S., Reid, A., \& Steen, C. (2010). Neuroticism and the architecture of the self: Exploring neuroticism as a moderator of the impact of ideal selfdiscrepancies on emotion. Journal of Personality, 78, 471-492.

Weiner, B. (1990). Attribution in personality psychology. In L.A. Pervin (Ed.), Handbook of personality. Theory and research (pp. 465-485). New York: The Guilford Press. 


\section{Autoestima y locus de causalidad como factores de vulnerabilidad para el desarrollo de autodiscrepancias actuales/ideales en la infancia tardía}

\section{Resumen}

Autodiscrepancias influyen en el bienestar psicológico y autoaceptación a través de varios dominios. Infancias intermedia y tardía representan la edad crítica para el desarrollo de autodiscrepancias (AA.DD.) Este estudio tiene como objetivo investigar antecedentes de autodiscrepancias actuales/ideales en los niños entre 9 y 11 años usando el diseño de medidas repetidas, con medidas en dos ocasiones diferentes. En la primera (T1), los niños $(N=261)$ completaron un cuestionario sobre la autoestima; desarrollamos la medida de AA.DD. actual/ideal alrededor de dominios del Modelo de los cinco grandes y del Cuestionario de Capacidades y Dificultades (SDQ); 4 meses después (T2) una submuestra $(N=96)$ hizo otra autocalificación. Los padres de estos niños $(N=195)$ determinaron sus propios sentimientos hacia sus hijos a través del Perfil de los Estados de Ánimo, tanto como por su locus de control percibido en cuanto a las conductas no deseadas de sus hijos; una submuestra de padres $(N=80)$ volvió a dar resultados 4 meses después. Análisis principal de componentes de autodiscrepancias de los niños en T1 produjo cuatro dominios: Intelecto, Estabilidad emocional, Control de impulsos y Sociabilidad. Con el paso de tiempo las discrepancias autoevaluadas se quedaron moderadamente estables. Al mismo tiempo, AA.DD. más altas en Intelecto especialmente se relacionaron con autoestima infantil más baja. Cross-lagged pattern analyses demostró que autoestima más baja predecía el incremento en AA.DD. infantiles, pero no al revés; además, cambio de niveles en AA.DD. se correlacionaron con el cambio de niveles en autoestima. Locus interno de causalidad percibido por los padres hacia sus hijos también explicó los cambios en AA.DD. infantiles. Sentimientos parentales de depresión explicaron incrementos en AA.DD. de las niñas. Hallazgos actuales apoyan aún más la relación entre la autoestima y las AA.DD., indican direcciones de relacionamiento a través del tiempo y sugieren posibles mecanismos a través de los cuales padres influyen en el desarrollo de la imagen que los niños tienen sobre sí mismos.

Palabras claves: desarrollo de la personalidad, autodiscrepancias, autoestima, locus de causalidad, correlaciones hijo/padres

Received: February 3, 2017 